\title{
Self-Organized Nanostructure Formation of III-V and IV Semiconductors with Bismuth
}

\author{
Hiroshi Okamoto \\ Graduate School of Science and Technology, Hirosaki University, 3 Bunkyo-cho, Hirosaki, \\ Aomori 036-8561, Japan \\ Email: okamoto@eit.hirosaki-u.ac.jp
}

\begin{abstract}
III-V and group IV semiconductor nanostructures such as quantum dots (QDs) are expected for various applications. In this study, effects of Bi supply during the deposition process on the self-organized nanostructure formation were examined for III-V and group IV semiconductor materials. It was found that $\mathrm{Bi}$ was successfully acted as a surfactant to form $\operatorname{In}(\mathrm{Ga})$ As QDs by MOVPE growth. By this method, QDs with superior optical quality were obtained. The unique features, such as ripening during the $\operatorname{In}(\mathrm{Ga}) \mathrm{As}$ QD formation and the phenomenon during the covering layer growth are discussed. As for the new approach on Ge-based nanostructure formation, high-density dot-like nanostructures were obtained by the low-temperature deposition sequence of $\mathrm{Bi}$ and $\mathrm{Ge}$ on $\mathrm{SiO}_{2}$ substrates. As the formation mechanism has not been revealed yet, we suggest hypotheses for that of the $\mathrm{Bi}$ and Ge system.
\end{abstract}

Keywords: Nanostructure, quantum dot, III-V, group IV semiconductor, surfactant, bismuth, InAs, InGaAs, germanium

\section{Introduction}

III-V and group IV semiconductor nanostructures such as quantum dots (QDs) are expected for various applications, e. g. a laser diode with a temperature-stable operation $[1,2]$, a single-photon source in quantum-cryptography system [3-6], a semiconductor optical amplifier (SOA) with high-speed operation [7], a SOA for a slow-light device [8], a solar cell with an ultra-high conversion efficiency [9-11], and a memory device with high reliability [12]. From the perspective of their fabrication, phenomena of selforganized nanostructure formation, such as Stranski-Krastanov (SK) growth has been utilized for that. One recent topic for the QD growth is a surfactant growth using Sb or Bi [13-21]. The main purpose of using the surfactants is to improve the QD density by reducing the migration length of adatoms. On the other hand, a counter discussion has also been held on $\mathrm{Sb}$ and Bi-surfactant for GaInP growth that the surfactants enhance the migration length [22]. These might indicate the effects of the surfactants are varied with growth conditions and methods used for their growth. We also have reported a novel growth method for In(Ga)As QDs using Bi as a surfactant. The beginning of using Bi for this purpose was as follows. In 1997, we were investigating Bi-containing III-V semiconductor materials such as GaAsBi, InAsBi, and InGaAsBi with the aim of developing new semiconductor materials which have temperature-insensitive energy gap [23-26]. In this period, the author found out following phenomena during the InAsBi/InAs and InGaAsBi/InP growth. For the InAsBi/InAs growth, Bi incorporation into InAs occurred in the limited growth temperature range at around $365^{\circ} \mathrm{C}$ and did not occur above $450^{\circ} \mathrm{C}$. As for the InGaAs/InP growth, Bi was hardly incorporated into InGaAs, and 3D growth tended to arise with the growth temperature around $480^{\circ} \mathrm{C}$. Another interesting phenomenon found in this system was that the partial decomposition of InGaAs appeared when Bi was supplied during the growth. Figure 1 (a) and (b) show scanning electron microscope (SEM) images of an InGaAs/InP sample grown with Bi supply for Auger electron spectroscopy (AES) analysis: Fig. 1 (a) shows the initial surface of the InGaAs (covered with a thin InP layer) with a hillock, and (b) shows the surface after Ar-ion spattering. In Fig. 1 (b), we have unexpectedly found some small particles in the InGaAs layer, and AES analysis revealed that the particles were In-rich InGaAs islands. In addition, Bi was detected only at the outermost surface, and not detected in the InGaAs layer. This fact means the supplying Bi during the InGaAs 
growth assisted the partial decomposition of InGaAs as a surfactant. We will refer to this phenomenon again in section 3.2. By considering these facts, the author had realized that Bi might be an ideal surfactant to form In(Ga)As QDs. Several years later, we have successfully grown In(Ga)As QDs using $\mathrm{Bi}$ as a surfactant $[27,28]$. By utilizing the superior optical quality of the QDs, we have reported fine structure and magneto-optics states in single InAs QDs [29, 30], single-photon emission from a QD in a microcavity structure [31], the cavity mode emission of QDs in a photonic-crystal-cavity structure [32, 33], and tunable slow-light characteristics using a waveguide structure with the QDs [34].

In this report, our study of the Bi surfactant growth for $\operatorname{In}(\mathrm{Ga}) \mathrm{As}$ QDs is reviewed with some new results, and the function of the Bi supply during the growth is reconsidered. We also show some our recent results on Ge-based nanostructure formation using Bi.

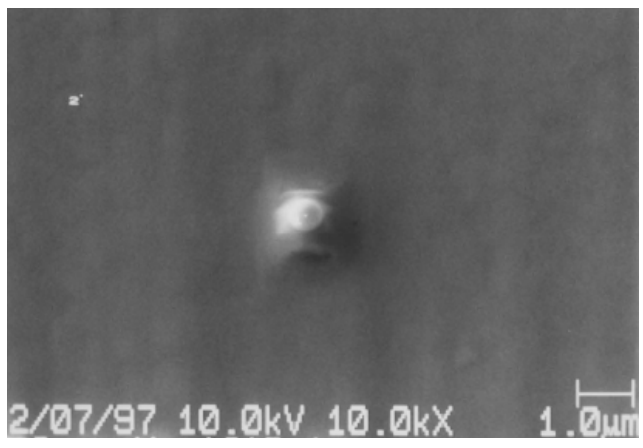

(a)

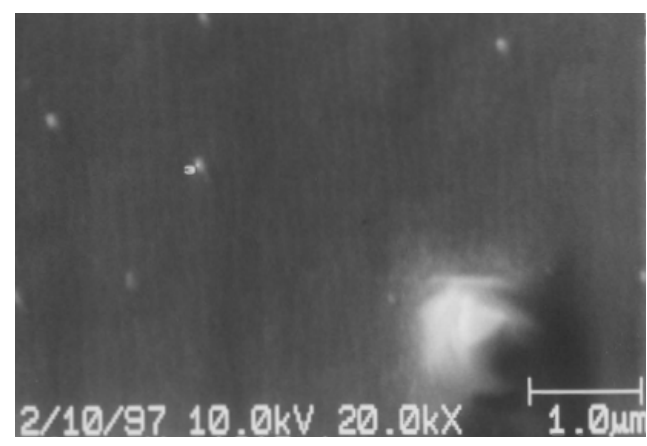

(b)

Figure 1. SEM images of an InGaAs layer grown on an InP substrate for AES analysis: Initial surface of the InGaAs covered with thin InP layer (with a hillock) (a), and the surface after Ar-ion spattering (small particles are unexpectedly appeared) (b). Small numerical characters ("2" and "3") appeared in these pictures are markers for AES analysis. This sample was grown for our previous study on Bi-containing alloy. Bi was supplied during the InGaAs-layer growth.

\section{$2 \quad$ Experimental Methods}

In(Ga)As-QD Samples were grown by conventional low-pressure metalorganic vapor phase epitaxy (MOVPE) on (100) GaAs substrates [28]. Trimethylindium (TMIn), triethylgallium (TEGa), triisopropylgallium (TIPGa), tertiarybutylphosphine (TBP), tertiarybutylarsine (TBAs), and Trimethylbismuth (TMBi) were the precursors. The novel growth sequence of this study was that the TMBi was supplied during QD and InGaAs-layer growth as a source of $\mathrm{Bi}$. The growth temperature for QDs and InGaAs layers was approximately $400{ }^{\circ} \mathrm{C}$, and that for the other layers was $580{ }^{\circ} \mathrm{C}$. The growth temperature was calibrated by using the melting points of InSb and bismuth. Here, TIPGa was used for the QD and InGaAs-layer growth because its decomposition temperature is lower than that of TEGa [35]. Growth sequence for the QD samples was as follows. After the growth of GaAs-buffer layer, InGaP-cladding layer (optional) and another GaAs layer were grown. Then the wafer was cooled down to $400^{\circ} \mathrm{C}$, dot-in-well (DWELL) structure or QDs with strain-reducing-layer (SRL) structure was grown. The InGaAs layers for both of the DWELL and SRL layers were grown by alternate supply of GaAs and InAs precursors. One-monolayer GaAs and submonolayer InAs were alternately grown by this method. During the growth, TMBi was supplied simultaneously except for some reference samples. The equivalent indium composition in the $\operatorname{In}_{\mathrm{x}} \mathrm{Ga}_{1-\mathrm{x}} \mathrm{As}$ layer was set at 0.08 or 0.12 as mentioned in following sections. Sample structures used for this study are schematically shown in Fig. 2. Two types of In(Ga)As-QD samples were grown. Structure-A2 in Fig. 2 includes the DWELL structure, in which QDs are embedded in an InGaAs quantum well (QW) [36]. On the other hand, Structure-B has the SRL structure, in which QDs are covered by an InGaAs layer (this also acts as QW layer) [37-40]. Although the naming has been done by the different way, the InGaAs layers of both structures act as SRL which elongate the emission wavelength of the QDs. Structure-A1 and Structure-A2 in Fig. 2 were used for atomic-force-microscope (AFM) observation and photoluminescence (PL) study, respectively. These 
structures were used to examine the basic characteristics of the QDs. On the other hand, Structure-B was used for a study to obtain high-density QDs. The differences of Structure-B from Structure-A2 were that the QDs were grown on GaAs layers and the existence of surface QDs for AFM observation. Because an in-situ growth monitor was not installed in our MOVPE chamber, the equivalent thicknesses for the QDs were determined by the growth rate and the composition of the InGaAs (InAs/GaAs) layers grown on GaAs substrate.

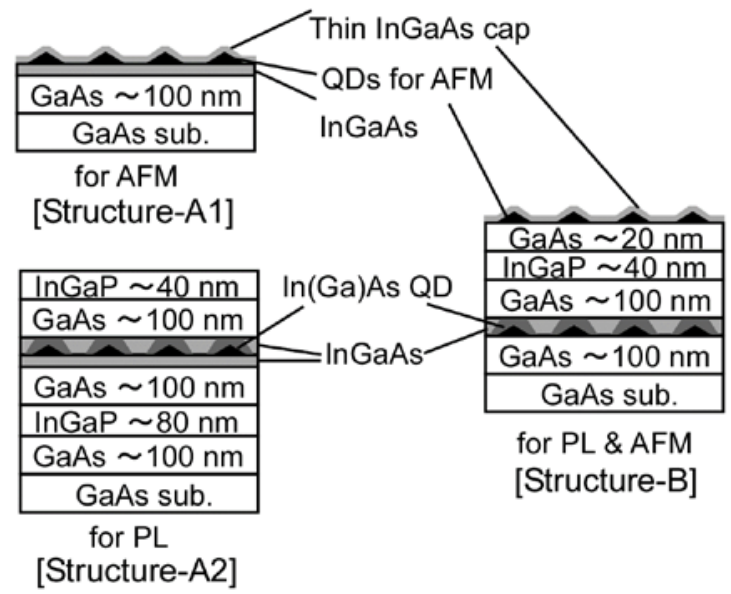

Figure 2. In(Ga)As-QD sample structures used for this study: Structure-A2 has DWELL structure, and StructureB has SRL structure. Structure-A1 was used for AFM observation.

Ge-based nanostructures were formed by resistive heating $(\mathrm{RH})$ and electron beam (EB) evaporation on $\mathrm{SiO}_{2}$ substrates. Here, Bi layers were deposited by the $\mathrm{RH}$ evaporation prior to the Ge deposition by the EB evaporation. Deposition thickness was monitored by a quartz crystal deposition controller during their growth.

Optical properties of the $\operatorname{In}(\mathrm{Ga}) \mathrm{As}-\mathrm{QD}$ samples were evaluated by PL measurement using a $532 \mathrm{~nm}$ laser excitation source $\left(0.8 \mathrm{~W} / \mathrm{cm}^{2}\right)$ and an InGaAs detector array cooled to $250 \mathrm{~K}$. Structural properties were observed by AFM.

\section{$3 \quad$ Results and Discussions}

\subsection{Characteristics of $\operatorname{In}(\mathrm{Ga})$ As Quantum Dots Grown by using Bi as a Surfactant}

Effect of the Bi supply during the $\operatorname{In}(\mathrm{Ga}) \mathrm{As}$ QD growth was examined by comparing the QD samples grown with and without Bi supply [28]. Structure-A2 in Fig. 2 with $\operatorname{In}_{0.12} \mathrm{Ga}_{0.88} \mathrm{As}$ QW layer was used. Figure 3 shows the PL spectra of the following three samples: grown without Bi supply (dotted curve), grown with Bi supply only for the well layer growth (broken curve), and grown with Bi supply for both of the well layer and QD growth (solid curve). As can be seen in this figure, PL intensity and peak wavelength of the samples grown with Bi supply were much stronger and longer than that of the sample grown without Bi supply. Furthermore, PL emission with telecom wavelength of $1.3 \mu \mathrm{m}$ was attained on the samples with Bi supply. One of the interesting points is that the PL characteristics were improved even by the Bi supply only for the well layer growth. This result means Bi supplied for the bottom half of the well layer growth remains on the surface during the next growth step of QDs. As for the effect of supplying $\mathrm{Bi}$ on the red shift of the PL wavelength, we have to consider the possibility of InAsBi-dot formation because InAsBi has narrower energy gap than that of InAs [25, 26]. To examine the Bi incorporation into the QDs and wells, SIMS analysis was performed. By this analysis, Bi was not detected both in the $\mathrm{QD}$ and well layers [28]. The effect of supplying $\mathrm{Bi}$ on the red shift will be discussed in next subsection. To improve the dot density, we have investigated growth conditions and 
layer structures, and found Structure-B in Fig. 2 with GaAs underlying layer is suitable for this purpose [28]. To evaluate the quality of the QDs with a density of $4 \times 10^{10} \mathrm{~cm}^{-2}$, temperature dependences of PL intensity and PL spectrum were examined. These results are shown in Figs. 4 and 5, respectively. In these figures, we can see that the thermal quenching of PL intensity is very small up to $100 \mathrm{~K}$, and the integrated PL intensity at $300 \mathrm{~K}$ is around $20 \%$ of that at $17 \mathrm{~K}$. These indicate that the densities of defects in QDs and surrounding layers are considerably low. The activation energy $E_{a}$ for the thermal quenching above $200 \mathrm{~K}$ is around $0.3 \mathrm{eV}$, which corresponds to the energy difference between the QD ground state of electrons and conduction band edge of the GaAs barrier layers.

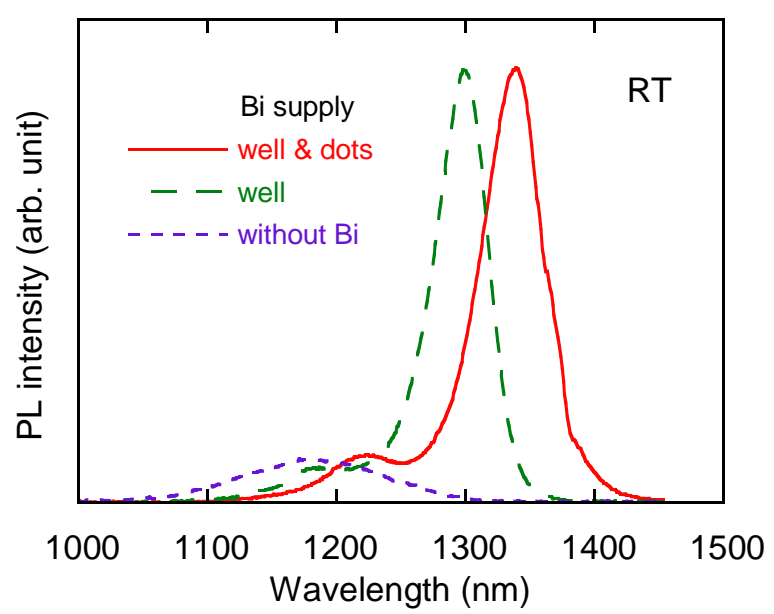

Figure 3. PL spectra for three $\operatorname{In}(\mathrm{Ga})$ As-QD samples: grown without Bi (dotted curve), grown with Bi supply only for the well layer growth (broken curve), and grown with Bi supply for both of the well layer and QD growth (solid curve).

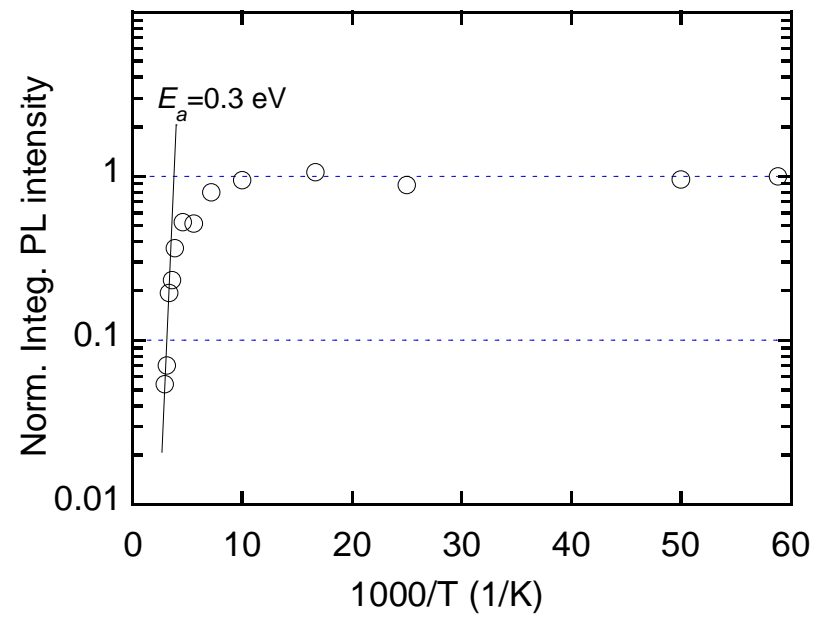

Figure 4. Temperature dependence of normalized integrated PL intensity for an $\operatorname{In}(\mathrm{Ga})$ As-QD sample with a dot density of $4 \times 10^{10} \mathrm{~cm}^{-2}$. 


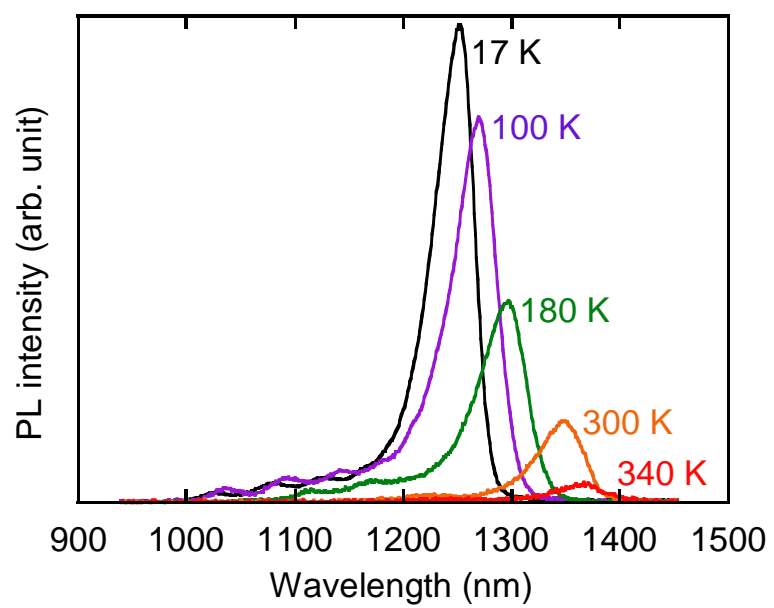

Figure 5. PL spectra of the $\operatorname{In}(\mathrm{Ga})$ As-QD sample correspond to the selected points plotted in Fig. 4.

\subsection{Unique Growth Features of In(Ga)As Quantum Dots using Bi as a Surfactant}

One of unique growth features of our QDs is fast ripening, which proceeds during the growth interruption just after the QD growth. Ripening is a process in which some islands grow at the expense of others by adatom-diffusion currents. Historically, this process was discussed with nearly equilibrium state of the two-phase system [41, 42]. Regarding QDs, ripening had attracted attention concerning the stability issue of II-VI QDs, since ripening proceeds even at room temperature for uncapped dots [43, 44]. For III-V QDs, ripening phenomena have also been observed during growth interruption or annealing process, and various results have been reported [45-49]. Although the ripening phenomena were complex and highly dependent on the materials and growth conditions, unified understanding of this phenomenon has been given by Suemune et al., that the ripening phenomena are not intrinsic nature of materials but are originating from excess surface adatoms or originating from oxide on the surface [50]. In this subsection, we show the effect of Bi surfactant on ripening, and also explain about another unique feature observed during the growth of covering InGaAs layers on the QDs.

Samples used to investigate the ripening phenomenon had Structure-B in Fig. 2 with an equivalent thickness of 1.9-ML $\operatorname{In}_{0.75} \mathrm{Ga}_{0.25}$ As initial QDs covered by $\operatorname{In}_{0.12} \mathrm{Ga}_{0.88}$ As SRLs. Surface QDs for AFM observation were covered with thin $\mathrm{In}_{0.12} \mathrm{Ga}_{0.88}$ As layers to prevent coalescence of the QDs during the cooling down process after the QD growth. Figures 6 (a) and (b) show the AFM images $\left(0.25 \times 0.5 \mu \mathrm{m}^{2}\right.$ area) and corresponding dot-height histograms of the samples: growth-interrupt times were 4 second (a), and 12 second (b) [51]. As can be seen in Figs 6 (a) and (b), uniformity of the QDs was much improved in this time span, and the height of the QDs (covered with thin InGaAs cap layers) was converged to $4.5-5 \mathrm{~nm}$. This result means that a partially stable condition to maintain the QD size appeared in this growth condition. In addition, the speed of ripening was considerably faster than that of the results reported for $\operatorname{In}(\mathrm{Ga})$ As QDs although the substrate temperature was lower than them [45, 48, 49]. We believe these features were caused by the Bi adatoms, which remained on the sample surface after the QD growth. The effect of $\mathrm{Bi}$ adatoms was examined by varying their coverage during the growth interruption [51]. Figure 7 shows the AFM image of the sample, for which Bi was supplied not only for the QD growth but also during the growth interruption. Large and low-density coalescent islands were observed. This result means ripening was accelerated by the excess Bi adatoms, and coalescence occurred subsequently. PL emission of the QDs was hardly observed with this sample. This result also indicates that the above mentioned partially-stable condition of the QD growth appears with an appropriate quantity of $\mathrm{Bi}$ adatoms, and $\mathrm{Bi}$ oversupply disrupts the condition. PL spectra of the samples corresponding to Figs. 6 (a) and (b) are shown in Fig. 8 [51]. QDs with narrower PL spectrum was obtained by the longer (12-second) growth interruption. This result also indicates the uniformity of the QDs was improved during the growth interruption. 


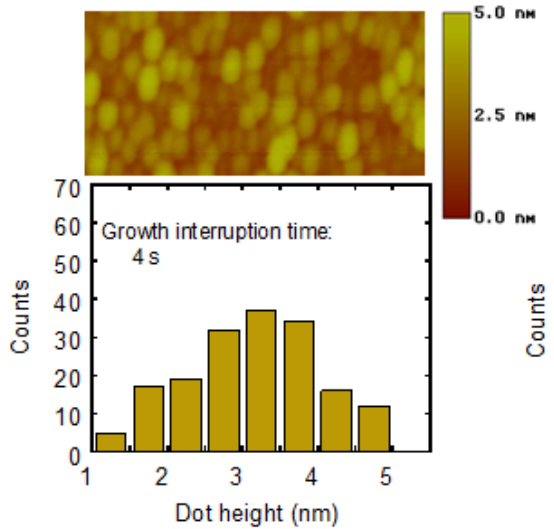

(a)

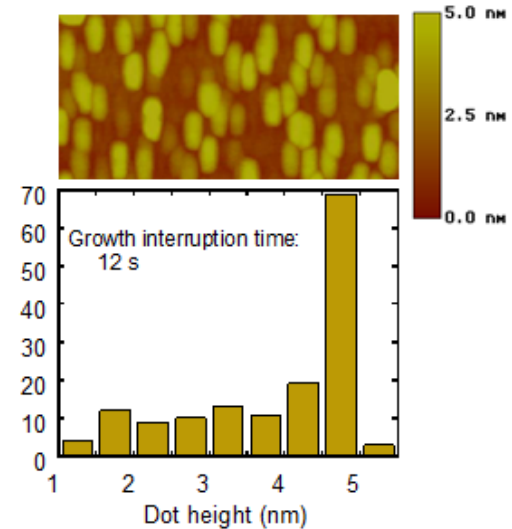

(b)

Figure 6. AFM images $\left(0.25 \times 0.5 \mu \mathrm{m}^{2}\right.$ area $)$ and corresponding dot-height histograms $\left(0.5 \times 0.5 \mu \mathrm{m}^{2}\right.$ area $)$ of the $\operatorname{In}(\mathrm{Ga})$ As QDs covered with thin InGaAs layers: growth-interrupt times were 4 seconds (a), and 12 seconds (b). Bi supply was stopped during the growth interruption.

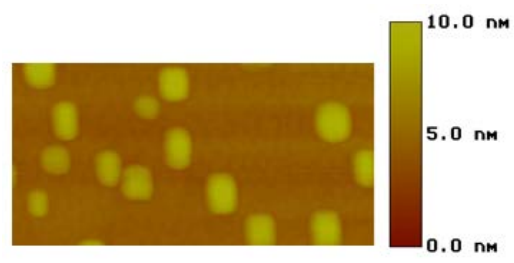

Figure 7. AFM image $\left(0.25 \times 0.5 \mu^{2}\right.$ area $)$ of an $\operatorname{In}(\mathrm{Ga})$ As-QD sample covered with thin InGaAs layers, for which Bi was supplied during the growth interruption. Growth interruption time was 12 seconds.

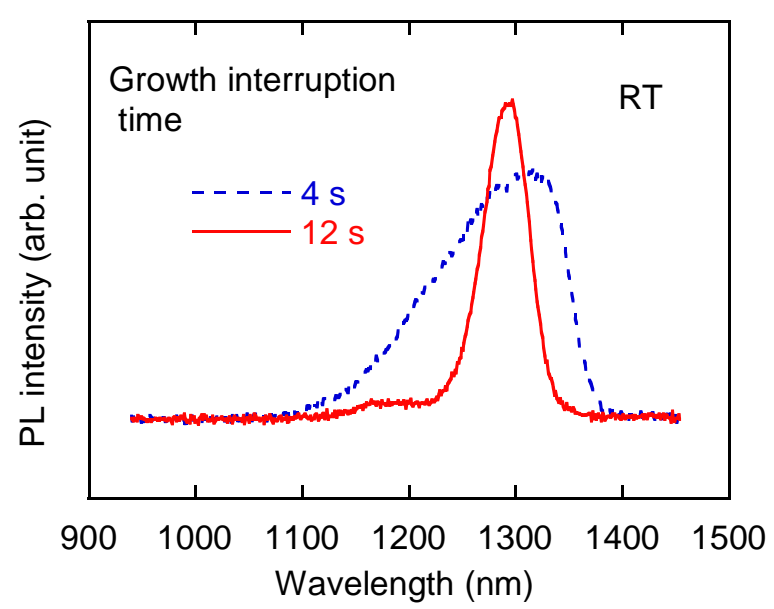

Figure 8. Room-temperature PL spectra of In(Ga)As-QD samples corresponding to Figs. 6 (a) and (b).

Another unique feature observed during the surfactant growth of the $\operatorname{In}(\mathrm{Ga})$ As QDs was a dependence of InGaAs covering layer thickness on PL-peak wavelength. The result is shown in Fig. 9. Samples with Structure-A2 in Fig. 2 with InAs initial dots and $\mathrm{In}_{0.08} \mathrm{Ga}_{0.92}$ As covering layers (upper part of QWs) were used for this experiment [28]. Longer PL-peak wavelength was observed with thicker covering layer thickness. Here, a point to be noted is that the indium content of the covering layer is much lower than 
that of the QD-SRL layers reported for $1.5 \mu \mathrm{m}$ light emission [40]. Thus, the large red shift shown in Fig. 9 is not likely to be explained by the simple strain-reducing effect of the InGaAs covering layers. One possible explanation for this phenomenon is based on the mechanism of activated alloy phase separation (AAPS), which has been reported for MBE-grown QDs with $\mathrm{InGa}(\mathrm{Al})$ As alloy layers [52]. According to Ref. 52, AAPS is the mechanism that the small dots formed by the first growth step are enlarged by the second-step of an alloy layer growth according to the phase separation driven by strain. In our case, this effect arises much stronger with much lower indium content InGaAs than the results in Ref. 52. We believe the phase separation during the InGaAs covering-layer growth was enhanced by Bi supply. This hypothesis corresponds to the fact that the partial phase separation of InGaAs was observed with Bi supply in our previous study of Bi-containing alloy, as mentioned in section 1 . To observe the growth characteristics of the InGaAs covering-layer growth, six samples with Structure-A1 in Fig. 2 were prepared: with two Bi supply conditions and three covering layer thickness. Figures 10 (a1-a3) and (b1b3) show the AFM images of the samples $\left(0.25 \times 0.5 \mu^{2}\right.$ area). Here, Bi was supplied only for the $\mathrm{In}_{0.12} \mathrm{Ga}_{0.88} \mathrm{As}$-layer growth (a1-a3), and $\mathrm{Bi}$ was supplied both for the $\operatorname{In}_{0.12} \mathrm{Ga}_{0.88}$ As-layer and the dot growth (b1-b3). The thickness of the $\mathrm{In}_{0.12} \mathrm{Ga}_{0.88} \mathrm{As}$-covering layers were four cycles for (a2) and (b2) and eight cycles for (a3) and (b3). Samples shown in (a1) and (b1) have no covering layer. In Figs. 10 (a2) and (b2), QDs covered with thin InGaAs layer have larger lateral size than that of in Figs. 10 (a1) and (b1), and their shapes are elliptical. This result indicates the InGaAs was selectively grown around the QDs with anisotropic nature, and the AAPS seemed to proceed in this while. Here, the dot shapes and densities of samples (a1) and (b1) might be modified during the cooling down process. However, because the deformation process results in forming larger QDs than before, this does not affect the basics of the discussion. Another unique feature appeared in Figs. 10 (a3) and (b3) was that the much more flat surface was obtained for the sample shown in (b3). The difference in growth condition between the samples was that the Bi was supplied during the QD growth or not (Bi was supplied for the covering layer growth for both of the samples). This fact means $\mathrm{Bi}$ adatoms remained after the QD growth affected a large effect on the covering InGaAs layer growth. This phenomenon might be understood by the fact that the $\mathrm{Bi} / \mathrm{As}$ rate for the QD growth was seven times larger than that of the covering InGaAs layer growth. This nature of the planarization is suitable for the multilayer QD growth. In fact, flat interfaces were observed in a 10-layer QD sample by transmission electron microscope (TEM) analysis (not shown) [28]. The growth sequence of the QD and SRL layer for Structure-B in Fig. 2, and the suggested growth nature are schematically illustrated in Fig. 11. First, Initial QD is grown with Biprecursor supply with high Bi/As-rate (a). Next, growth is interrupted, and Bi supply is stopped. Ripening proceeds and uniformity of the QDs is improved during the growth interruption (b). Then InGaAs covering layer (SRL layer) is grown by alternate supply of GaAs and InAs precursors (c). In this while, Bi precursor is supplied with low Bi/As rate. In the initial step of (c), InGaAs was selectively grown around the QDs and AAPS proceeds. This results in the formation of InGaAs QDs. Finally, surface planarization occurs spontaneously during the rest of covering layer growth.

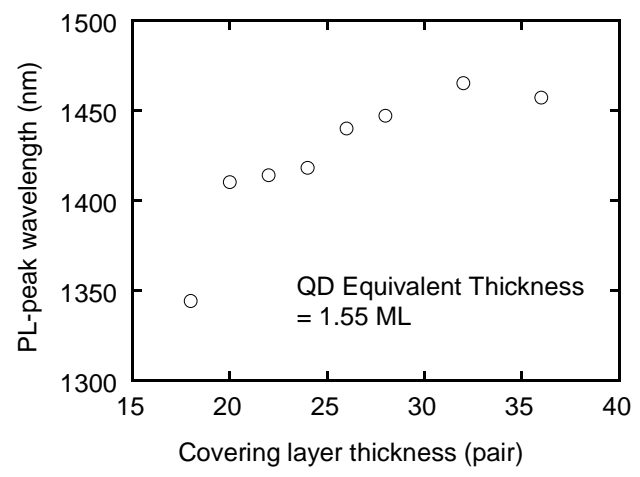

Figure 9. Dependence of $\operatorname{In}_{0.08} \mathrm{Ga}_{0.92}$ As covering layer thickness on PL-peak wavelength. 


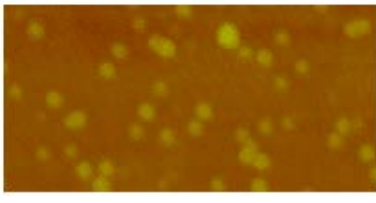

(a1)

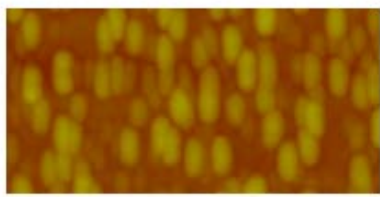

(a2)

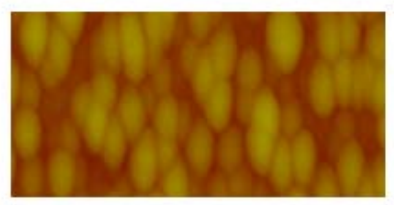

(a3)

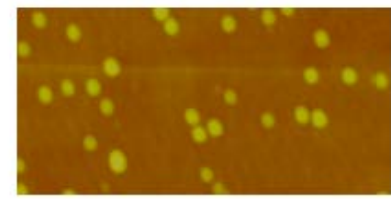

(b1)

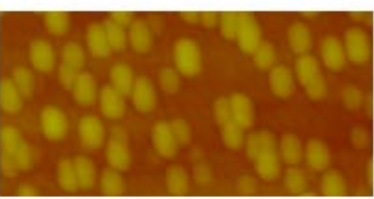

(b2)

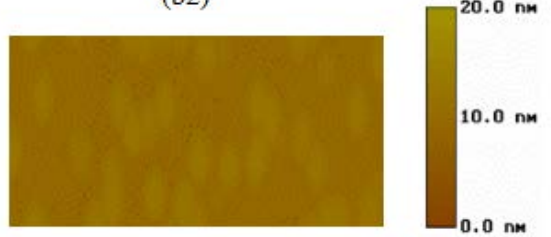

(b3)

Figure 10. AFM images of the $\operatorname{In}(\mathrm{Ga}) \mathrm{As}-\mathrm{QD}$ samples $\left(0.25 \times 0.5 \mathrm{\mu m}^{2}\right.$ area $)$ with two Bi supply conditions and three covering layer thickness. Bi was supplied for InGaAs layers (a1-a3), and Bi was supplied for both of the InGaAs layers and InAs-dots (b1-b3). Covering layers were as follows: No covering layer (a1) and (b1), thin covering layers with 4-cycle $\operatorname{In}_{0.12} \mathrm{Ga}_{0.88} \mathrm{As}$ (a2) and (b2), and that with 8-cycle $\operatorname{In}_{0.12} \mathrm{Ga}_{0.88} \mathrm{As}$ (a3) and (b3). Note that the dot shapes and densities of samples shown in (a1) and (b1) might be modified during the cooling down process.

(a) Initial QD growth

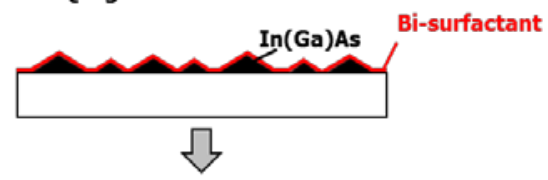

(b) Growth interruption

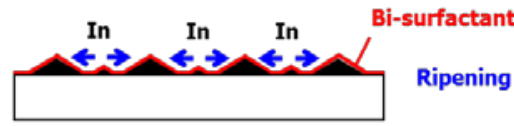

Љ

(c) InGaAs-covering layer growth
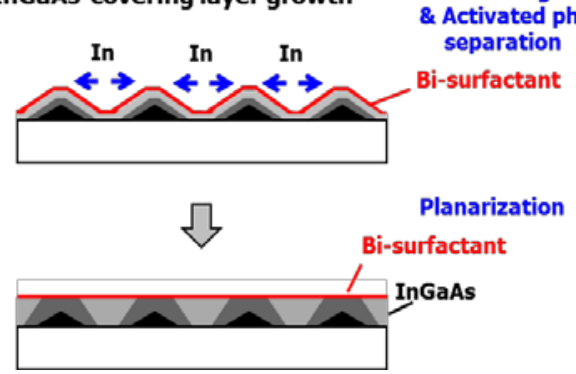

ON (Low Bi/As rate)

\section{Bi supply}

ON (High Bi/As rate)

OFF

(Bi remains on the surface)

ON(Low Bi/As rate)

Figure 11. Growth sequence of the $\operatorname{In}(\mathrm{Ga})$ As QD and SRL layer for Structure-B in Fig. 2 and suggested growth nature. 


\subsection{Ge-based Nanostructure Formation using Bi}

To examine the effect of $\mathrm{Bi}$ on the nanostructure formation of group IV semiconductors, Bi and Ge layers were deposited on $\mathrm{SiO}_{2}$ substrates. The purpose of this study is to obtain high-density nanodots with low-temperature process for the applications such as floating gate memories. Here, Bi was deposited prior to Ge deposition. Figures 12 (a-d) show the AFM images of the samples deposited in the temperature range from 110 to $170^{\circ} \mathrm{C}$. In this case, Bi and Ge deposition thicknesses $\left(d_{B i}\right.$ and $\left.d_{G e}\right)$ were fixed at 0.5 and $1.2 \mathrm{~nm}$, respectively. AFM scanning areas were $0.5 \times 1.0 \mathrm{\mu m}^{2}$. Dot-like structures were observed as low as $110^{\circ} \mathrm{C}$ deposition. This temperature is much lower than that of the reported value for crystalline-Ge-island formation on $\mathrm{SiO}_{2}$ substrates [53]. Next, dependencies of $d_{B i}$ and $d_{G e}$ on the structure were examined. AFM observation results are summarized in Fig. 13. We can see a unique dependence in this figure. In the case that $d_{G e}$ was fixed at $1.2 \mathrm{~nm}$ and $d_{B i}$ was varied, dot-like structure appeared when $d_{B i}$ was set at $0.5 \mathrm{~nm}$, and not appeared when $d_{B i}$ s were set at 0.1 or $0.2 \mathrm{~nm}$. In contrast, dot-like structure appeared with thinner $d_{B i}$ of $0.2 \mathrm{~nm}$ when $d_{G e}$ was set at $0.6 \mathrm{~nm}$. These results mean the condition of nanostructure formation is not directly related to $d_{B i}$ but related to the combination of $d_{B i}$ and $d_{G e}$. These facts suggest the nature of the nanostructure formation is not based on surfactantmediated growth but based on other mechanisms: dot-like structure should appear with the condition of $d_{B i}=0.2 \mathrm{~nm}$ and $d_{G e}=1.2 \mathrm{~nm}$ if its nature of formation is the surfactant-mediated growth. As the mechanism has not been revealed yet, we suggest two hypotheses. One is that a mass transport of the deposited atoms is enhanced by the formation of $\mathrm{Ge}$ and $\mathrm{Bi}$ mixture with a specific composition. A problem for this hypothesis is that there have been no reports which indicate Ge and Bi mixture has a eutectic characteristic. Another hypothesis is that the dot-like structures are mainly composed of Bi. In this case, we have to consider the following results shown in Fig. 13. First, the dot-like structure did not appear with the condition of $d_{B i}=0.5 \mathrm{~nm}$ and $d_{G e}=0 \mathrm{~nm}$ by which only Bi layer was deposited. This result means Ge layer is needed to form the dot-like structure. Next, dot-like structure appeared with the condition of $d_{B i}=0.2 \mathrm{~nm}$ and $d_{G e}=0.6 \mathrm{~nm}$ but did not appear with the condition of $d_{B i}=0.2 \mathrm{~nm}$ and $d_{G e}=1.2 \mathrm{~nm}$, as indicated before. These results mean relatively thin Ge layer is needed to form the structure. One possible hypothesis for this is that the surface free energy of deposited layer (first step: $\mathrm{Bi}$ ) is modified by the deposition of thin Ge layer. In this case, however, we could not explain the reason why the appropriate Ge thickness exists. Further investigations such as analysis of the dot-like-structure composition are needed for this materials system.

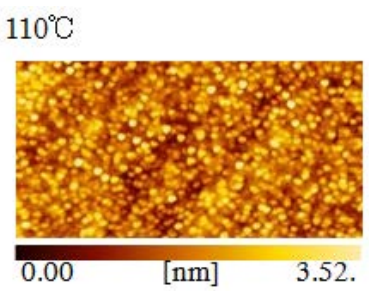

(a)

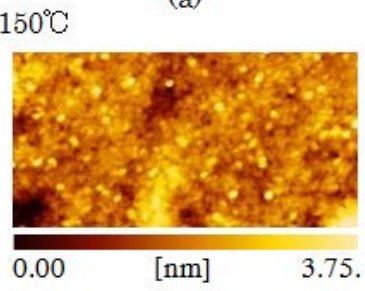

(c)

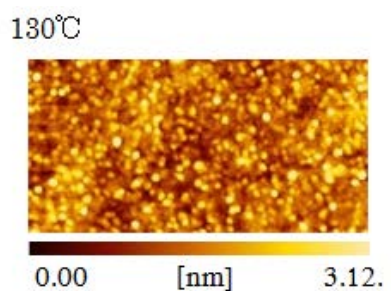

(b)

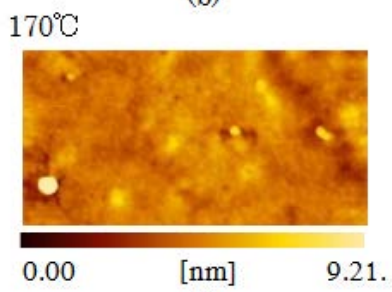

(d)

Figure 12. AFM images of the samples, for which $\mathrm{Bi}$ and Ge layers were deposited in the temperature range from 110 to $170^{\circ} \mathrm{C}$. Bi and Ge thicknesses were fixed at 0.5 and $1.2 \mathrm{~nm}$, respectively. AFM scanning areas were $0.5 \times 1.0$ $\mu \mathrm{m}^{2}$. 


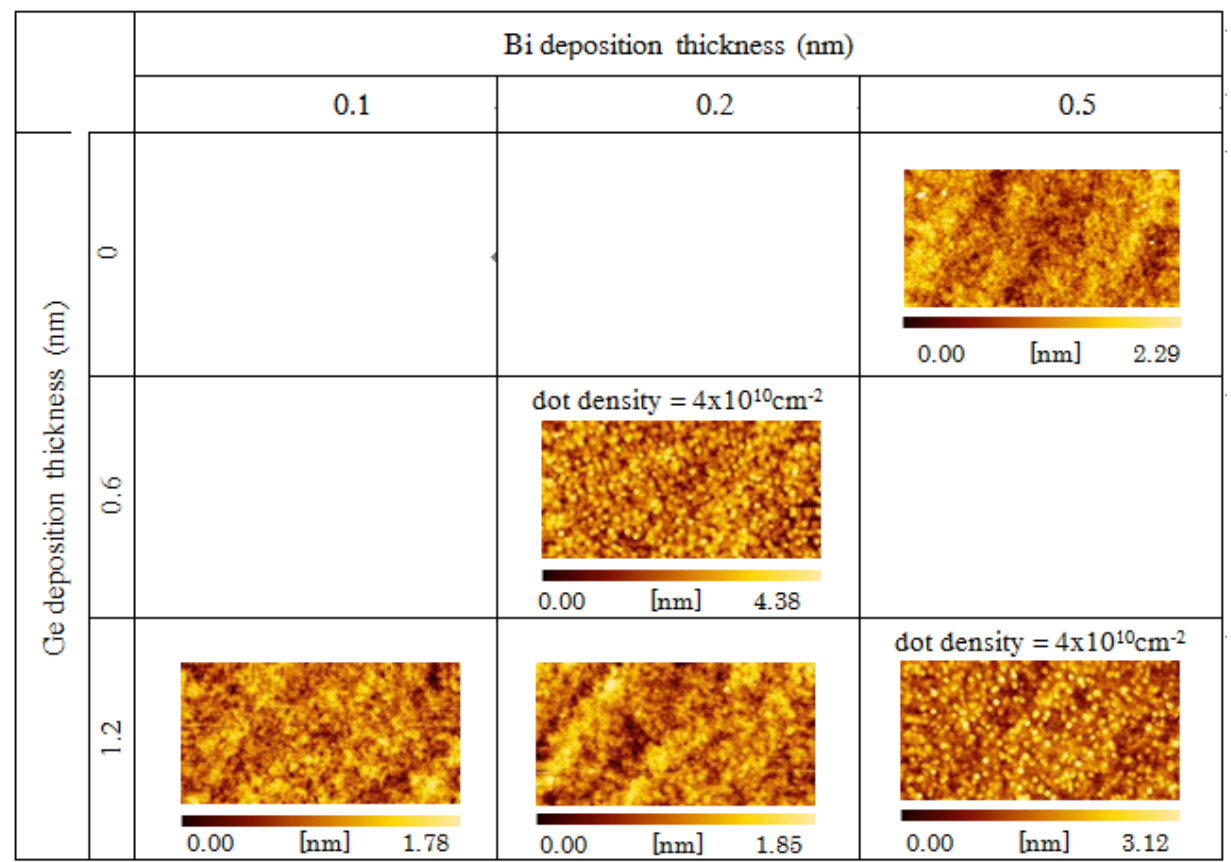

Figure 13. AFM observation results of the samples for which $\mathrm{Bi}$ and $\mathrm{Ge}$ deposition thickness were varied. The deposition temperature was fixed at $130^{\circ} \mathrm{C}$.

\section{Conclusions}

Effects of Bi on self-organized nanostructure formation for III-V and group IV semiconductor materials were studied. Bi was successfully acted as a surfactant to form $\operatorname{In}(\mathrm{Ga})$ As QDs. By this surfactant growth, QDs with telecommunication wavelength range and superior optical quality were obtained. The unique features, such as ripening during the QD formation and the phenomenon during the covering layer growth were discussed. As for the new approach on Ge-based nanostructure formation, highdensity dot-like nanostructures were observed on the samples which were made by low-temperature deposition of $\mathrm{Bi}$ and Ge. As the formation mechanism has not been revealed yet, we suggested two hypotheses for that of the $\mathrm{Bi}$ and $\mathrm{Ge}$ system and discussed some problems. Although the formation mechanism may quite differ between the $\operatorname{In}(\mathrm{Ga}) \mathrm{As}$ QDs and the Ge-based nanostructures, Bi is an attractive material to form self-organized nanostructures.

Acknowledgements. The author would like to thank T. Tawara, K. Tateno, G. Zhang, H. Gotoh, H. Kamada, N. I. Cade, T. Yamaguchi, and T. Sogawa for their useful discussions, and also thank S. Yamaya, Y. Kobayashi, K. Hayashi, Y. Suzuki, and K. Takita for their technical assistance. This work was partially supported by JSPS KAKENHI Grant Number 26420264.

\section{References}

1. M. V. Maximov, N. N. Ledentsov, V. M. Ustinov, Zh. I. Alferov, and D. Bimberg, "GaAs-based $1.3 \mu \mathrm{m}$ InGaAs quantum dot lasers: A status report," Journal of Electronic Materials, vol. 29, no. 5, pp. 476-486, 2000.

2. M. Ishida, N. Hatori, K. Otsubo, T. Yamamoto, Y. Nakata, H. Ebe, M. Sugawara, and Y. Arakawa, "Lowdriving-current temperature-stable $10 \mathrm{Gbit} / \mathrm{s}$ operation of p-doped $1.3 \mu \mathrm{m}$ quantum dot lasers between 20 and 90 C," Electronics Letters, vol. 43, no. 4, pp. 219-221, 2007.

3. E. Moreau, I. Robert, J. M. Gérard, I. Abram, L. Manin, and V. Thierry-Mieg, "Single-mode solid-state single photon source based on isolated quantum dots in pillar microcavities," Applied Physics Letters, vol. 79, no. 18, pp. 
2865-2867, 2001.

4. C. Santori, D. Fattal, J. Vuckovic, G. S. Solomon, and Y. Yamamoto, "Indistinguishable photons from a singlephoton device," Nature, vol. 419, no. 10, pp. 594-597, 2002.

5. K. Takemoto, Y. Sakuma, S. Hirose, T. Usuki, N. Yokoyama, T. Miyazawa, M. Takatsu, and Y. Arakawa, "Non-

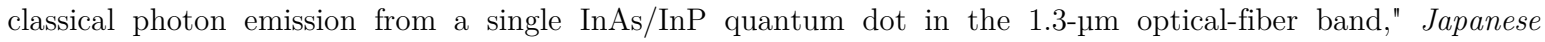
Journal of Applied Physics, vol. 43 part 2, no. 7B, pp. L993-L995, 2004.

6. T. Miyazawa, K. Takemoto, Y. Sakuma, S. Hirose, T. Usuki, N. Yokoyama, M. Takatsu, and Y. Arakawa, "Single-photon generation in the 1.55- $\mu \mathrm{m}$ optical-fiber band from an InAs/InP quantum dot," Japanese Journal of Applied Physics, vol. 44, no. 20, pp. L620-L622, 2005.

7. M. Sugawara, H. Ebe, N. Hatori, and M. Ishida, "Theory of optical signal amplification and processing by quantum-dot semiconductor optical amplifiers," Physical Review B, vol. 69, no. 23, pp. 235332_1-235332_39, 2004.

8. C. J. Chang-Hasnain, P. C. Ku, J. Kim, and S. L. Chuang, "Variable optical buffer using slow light in semiconductor nanostructures," Proceedings of the IEEE, vol. 91, no. 11, pp. 1884-1897, 2003.

9. A. Luque and A. Marti, "Increasing the efficiency of ideal solar cells by photon induced transitions at intermediate levels," Physical Review Letters, vol. 78, no. 26, pp. 5014-5017, 1997.

10. A. Marti, E. Antolin, C. R. Stanley, C. D. Farmer, N. Lopez, P. Diaz, E. Canovas, P. G. Linares, and A. Luque, "Production of photocurrent due to intermediate-to-conduction-band transitions: A demonstration of a key operating principle of the intermediate-band solar cell," Physical Review Letters, vol. 97, no. 24, pp. 24770_1$24770 \_4,2006$

11. S. Tomić, T. S. Jones, and Nicholas M. Harrison, "Absorption characteristics of a quantum dot array induced intermediate band: Implications for solar cell design," Applied Physics Letters, vol. 93, no. 26, pp. 263105_1263105_3, 2008.

12. S. Tiwari, F. Rana, H. Hanafi, A. Hartstein, E. F. Crabbe', and K. Chan, "A silicon nanocrystals based memory," Applied Physics Letters, vol. 68, no. 10, pp. 1377-1379, 1996.

13. Y. Sun, S.F. Cheng, G. Chen, R.F. Hicks, J. G. Cederberg, and R. M. Biefeld, "The effect of antimony in the growth of indium arsenide quantum dots in gallium arsenide (001)," Journal of applied physics, vol. 97, no.5, pp. 053503_1-053503_6, 2005.

14. K. Yamaguchi, T. Kanto, "Self-assembled InAs quantum dots on GaSb/GaAs(001) layers by molecular beam epitaxy," Journal of Crystal Growth, vol. 275, no. 1-2, pp. e2269-e2273, 2005.

15. D. Guimard, M. Nishioka, S. Tsukamoto, and Y. Arakawa, "Effect of antimony on the density of InAs/Sb:GaAs(100) quantum dots grown by metalorganic chemical-vapor deposition," Journal of Crystal Growth, vol. 298, no, pp. 548-552, 2007.

16. B N Zvonkov, I A Karpovich, N V Baidus, D O Filatov, S V Morozov, and Yu Yu Gushina, "Surfactant effect of bismuth in the MOVPE growth of the InAs quantum dots on GaAs," Nanotechnology, vol. 11, no. 4, pp. 221226,2000

17. Vaishno D. Dasika, E. M. Krivoy, H. P. Nair, S. J. Maddox, K. W. Park, D. Jung, M. L. Lee, E. T. Yu, and S. R. Bank, "Increased InAs quantum dot size and density using bismuth as a surfactant," Applied Physics Letters, vol. 105 , no. 25, pp. 253104, 2014.

18. C. S. Peng, Q. Huang, W. Q. Cheng, and J. M. Zhou, "Improvement of Ge self-organized quantum dots by use of Sb surfactant," Applied Physics Letters, vol. 72, no. 20, pp. 2541-2543, 1998.

19. J. Konle, H. Presting, H. Kibbel, F. Banhart, "Growth studies of Ge-islands for enhanced performance of thin film solar cells," Materials Science and Engineering: B, vol. 89, no. 1-3, pp. 160-165, 2002.

20. A. Portavoce, I. Berbezier, and A. Ronda, "Sb-surfactant-mediated growth of Si and Ge nanostructures," Physical Review B, vol. 69, no. 15, pp. 155416_1-155416_8, 2004.

21. A.A. Tonkikh, N.D. Zakharov, A.V. Novikov, K.E. Kudryavtsev, V.G. Talalaev, B. Fuhrmann, H.S. Leipner, and P. Werner, "Sb mediated formation of Ge/Si quantum dots: Growth and properties," Thin Solid Films, vol. 520, no.8, pp. 3322-3325, 2012.

22. R. T. Lee, C. M. Fetzer, S. W. Jun, D. C. Chapman, J. K, Shurtleff, G. B. Stringfellow, Y. W. Ok, and T. Y. Seong, "Enhancement of compositional modulation in GaInP epilayers by the addition of surfactants during organometallic vapor phase epitaxy growth," Journal of Crystal Growth, vol. 233, no. 3, pp. 490-502, 2001. 
23. K. Oe and H. Asai, "Proposal on a Temperature-Insensitive Wavelength Semiconductor Laser, "IEICE TRANSACTIONS on Electronics, vol. E79-C, no. 12, pp. 1751-1759, 1996.

24. K. Oe, H. Okamoto, "New semiconductor alloy $\mathrm{GaAs}_{1-\mathrm{x}} \mathrm{Bi}_{\mathrm{x}}$ grown by metal organic vapor phase epitaxy," Japanese Journal of Applied Physics, vol. 37 Part 2, no. 11A, pp. L1283-L1285, 1998.

25. H. Okamoto and K. Oe, "Growth of metastable alloy InAsBi by low-pressure MOVPE," Japanese Journal of Applied Physics, vol. 37, no. 3B, pp. 1608-1613, 1998.

26. H. Okamoto and K. Oe, "Structural and energy-gap characterization of metalorganic-vapor-phase-epitaxy-grown InAsBi," Japanese Journal of Applied Physics, vol. 38, no. 2B, pp. 1022-1025, 1999.

27. H. Okamoto, H. Gotoh, N. I. Cade, H. Kamada, and T. Sogawa, "MOVPE growth of In(Ga)As-quantum dots using Bi as a surfactant," in Extended Abstract of 53rd Spring Meeting, 2006; Japan Society of Applied Physics and Related Societies, 25p-T-19 [in Japanese], 2006.

28. H. Okamoto, T. Tawara, H. Gotoh, H. Kamada, and T. Sogawa, "Growth and characterization of telecommunication-wavelength quantum dots using Bi as a surfactant," Japanese Journal of Applied Physics, vol. 49 Part 1, no. 2B, pp. 06GJ01_1-06GJ01_6, 2010.

29. N. I. Cade, H. Gotoh, H. Kamada, H. Tawara, T. Sogawa, H. Nakano, and H. Okamoto, "Charged exciton emission at $1.3 \mu \mathrm{m}$ from single InAs quantum dots grown by metalorganic chemical vapor deposition," Applied Physics Letters, vol. 87, no. 17, pp. 172101_1-172101_3, 2005.

30. N. I. Cade, H. Gotoh, H. Kamada, H. Nakano, and H. Okamoto, "Fine structure and magneto-optics of exciton, trion, and charged biexciton states in single InAs quantum dots emitting at 1.3 um," Physical Review B, vol. 73, no. 11, pp. 115322_1-115322_7, 2006.

31. T. Yamaguchi, T. Tawara, H. Kamada, H. Gotoh, H. Okamoto, H. Nakano, and O. Mikami, "Single-photon emission from single quantum dots in a hybrid pillar microcavity," Applied Physics Letters, vol. 92, no. 8, pp. 081906_1-081906_3, 2008.

32. T. Tawara, H. Kamada, S. Hughes, H. Okamoto, M. Notomi, and T. Sogawa, "Cavity mode emission in weakly coupled quantum dot - cavity systems," Optics Express, vol. 17, no. 8, pp. 6643-6654, 2009.

33. T. Tawara, H. Kamada, T. Tanabe, T. Sogawa, H. Okamoto, P. Yao, P. K. Pathak, and S. Hughes, "CavityQED assisted attraction between a cavity mode and an exciton mode in a planar photonic-crystal cavity," Optics Express vol. 18, no 3, pp. 2719-2728, 2010.

34. H. Gotoh, S. W. Chang, S. L. Chuang, H. Okamoto, and Y. Shibata, "Tunable Slow Light of 1.3um Region in Quantum Dots at Room Temperature," Japanese Journal of Applied Physics, vol. 46, no. 4B, pp. 2369-2372, 2007.

35. P. A. Lane, T. Martin, R. W. Freer, P. D. J. Calcott, C. R. Whitehouse, A. C. Jones, and S. Rushworth, "Triisopropyl gallium: A very promising precursor for chemical beam epitaxy," Applied Physics Letters, vol. 61, no. 3, pp. 285-287, 1992.

36. L. f. Lester, A. Stintz, H. Li, T. C. Newell, E. A. Pease, B. A. Fuchs, and K. J. Malloy, "Optical characteristics of 1.24-um InAs quantum-dot laser diodes," IEEE Photonics Technol. Letters, vol. 11, no. 8, pp. 931-933, 1999.

37. K. Nishi, H. Saito, S. Sugou, and J.-S. Lee, "A narrow photoluminescence linewidth of $21 \mathrm{meV}$ at $1.35 \mu \mathrm{m}$ from strain-reduced InAs quantum dots covered by $\operatorname{In}_{0.2} \mathrm{Ga}_{0.8} \mathrm{As}$ grown on GaAs substrates," Applied Physics Letters, vol. 74, no. 8, pp. 1111-1113, 1999.

38. V. M. Ustinov, N. A. Maleev, A. E. Zhukov, A. R. Kovsh, A. Yu. Egorov, A. V. Lunev, B. V. Volovik, I. L. Krestnikov, Yu. G. Musikhin, N. A. Bert, P. S. Kop'ev, Zh. I. Alferov, N. N. Ledentsov, and D. Bimberg,

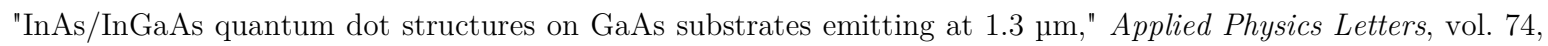
no. 19, pp. 2815-2817, 1999.

39. K. Mukai, and M. Sugawara, "Suppression of temperature sensitivity of interband emission energy in 1.3- $\mu \mathrm{m}-$ region by an InGaAs overgrowth on self-assembled InGaAs/GaAs quantum dots," Applied Physics Letters, vol. 74, no. 26, pp. 3963-3965, 1999.

40. J. Tatebayashi, M. Nishioka, and Y. Arakawa, "Over $1.5 \mu \mathrm{m}$ light emission from InAs quantum dots embedded in InGaAs strain-reducing layer grown by metalorganic chemical vapor deposition," Applied Physics Letters, vol. 78, no. 22, pp. 3469-3471, 2001.

41. W. Ostwald, "Über die vermeintliche isometric des roten undgelben quecksilberxyds und die oberflachenspannung fester körper," Zeitschrift für Physikalische Chemie, vol. 34, pp. 495-503, 1900.

42. P. W. Voorhees, "Ostwald ripening of two-phase mixtures," Annual Review of Materials Science, vol. 22, pp. 197-215, 1992. 
43. S. H. Xin, P. D. Wang, A. Yin, C. Kim, M. Dobrowolska, J.L. Merz, and J. K. Furdyna, "Formation of selfassembling CdSe quantum dots on ZnSe by molecular beam epitaxy," Applied Physics Letters, vol. 69, no. 25, pp. 3884-3886, 1996.

44. S. Lee et al, "Dynamics of ripening of self-assembled II-VI semiconductor quantum dots," Physical Review Letters, vol. 81, no. 16, pp. 3479-3482, 1998.

45. Y. Kim, B. D. Min, and E. K. Kim, "Ripening suppression and large photoluminescence blueshift in aligned InGaAs quantum dots on a vicinal (100) GaAs substrate," Journal of applied physics, vol. 85, no. 4, pp. 21402145,1999 .

46. K. Pötschke, L. Müller-Kirsch, R. Heitz, R. L. Sellin, U. W. Pohl, D. Bimberg, N. Zakharov, and P. Werner, "Ripening of self-organized InAs quantum dots," Physica E, vol. 21, no. 2-4, pp. 606-610, 2004.

47. T. J. Krzyzewski, and T. S. Jones, "Ripening and annealing effects in InAs/GaAs(001) quantum dot formation," Journal of applied physics, vol. 96, no. 1, pp. 668-674, 2004.

48. T. Kaizu, M. Takahashi, K. Yamaguchi, J. Mizuki, "Modification of InAs quantum dot structure during annealing," Journal of Crystal Growth, vol. 301-302, pp. 248-251, 2007.

49. R. Kremzow, M. Pristovsek, and M. Kneissl, " Ripening of InAs quantum dots on GaAs (001) investigated with in situ scanning tunneling microscopy in metal-organic vapor phase epitaxy," Journal of Crystal Growth, vol. 310, no. 23, pp. 4751-4753, 2008.

50. I. Suemune, K. Yoshida, H. Kumano, T. Tawara, A. Ueta, and S. Tanaka, "II-VI quantum dots grown by MOVPE," Journal of Crystal Growth, vol. 248, pp. 301-309, 2003.

51. H. Okamoto T. Tawara, K. Tateno, H. Gotoh, H. Kamada, and T. Sogawa, "Distinctive feature of ripening during growth interruption of InGaAs quantum dot epitaxy using Bi as a surfactant," Japanese Journal of Applied Physics, vol. 50, no. 6, pp. 06GH07_1-06GH07_4, 2011.

52. M. V. Maximov, A. F. Tsatsul'nikov, B. V. Volovic, D. S. Sizov, Yu. M. Shernyakov, I. N. Kaiander, A. E. Zhukov, A. R. Kovsh, S. S. Mikhrin, v. M. Ustinov, Zh. I. Alferov, R. Heitz, V. A. Shchukin, N. N. Ledentsov, D. Bimberg, Yu. G. Musikhin, and W. Neumann, "Tuning quantum dot properties by activated phase separation of an InGa(Al)As alloy grown on InAs stressors," Physical Review B, vol. 62, no. 24, pp. 16671-16680, 2000.

53. Y. Wakayama, T. Tagami1, and S, Tanaka, "Three-dimensional islands of Si and Ge formed on SiO2 through crystallization and agglomeration from amorphous thin films," Thin Solid Films, vol. 350 no. 1-2, pp. 300-307, 1999. 